\title{
Upbringing of Student Teachers in Extracurricular Activities in the Context of Distance Learning
}

\author{
https://doi.org/10.3991/ijet.v16i08.19103 \\ Roman S. Nagovitsyn ${ }^{(凶)}$ \\ Glazov State Pedagogical Institute, Glazov, Russia \\ gto18@mail.ru \\ Roza A. Valeeva \\ Kazan Federal University, Kazan, Russia \\ Aleksander Y. Osipov, Mikhail D. Kudryavtsev, \\ Larisa V. Zakharova \\ Siberian Federal University, Krasnoyarsk, Russia
}

\begin{abstract}
Introduction of distance technologies is necessary in the professional training of students, despite various assessments of its effectiveness. The purpose of the study is to develop the students' upbringing system in a distance format and experimentally prove its impact on the main directions of future teachers' upbringing, in comparison with off-line extracurricular activities. 156 undergraduate students took part in the experiment. Experimental research is the author's paradigm for the formation of youth upbringing in extracurricular activities, which includes six synergistically interrelated areas. The students' upbringing system developed in the study was tested in two formats of implementation: in off-line format at the first stage of the study and in distance format at the second stage. The statistical data obtained confirm the effectiveness of extracurricular activities for the formation of the future teachers' upbringing only in off-line format. The introduction of distance technologies in the implementation of upbringing extracurricular activities does not have a positive effect on students, but in some areas has an opposite negative effect. The practical significance of the study is determined by the introduction of a self-analysis and monitoring system into the educational process through the use of Facebook and VKontakte social networks.
\end{abstract}

Keywords - Upbringing, students, extracurricular activities, distance technologies

\section{Introduction}

A paradoxical situation has developed in Russian society today in relation to upbringing of young people [1]. On the one hand, the priority task of the Russian Federation is the formation of new generations with knowledge and skills meeting the requirements of the XXI century, sharing traditional moral values [2]. The key tool for solving 
this problem is upbringing of the younger generation, aimed at forming of a harmonious person, as well as mature, responsible citizen of the state combining love for the big and small homeland, national and ethnic identity, respect for culture and traditions of people living nearby [3]. On the other hand, the solution of the main tasks of the state policy in the field of upbringing, stated in the strategy for the development of upbringing in the Russian Federation, is oriented only by 2025 [4].

The main social institution for the younger generation upbringing is the system of general secondary and higher education $[5,6]$. In turn, it is the teacher training universities and institutes that are the main guides to the systematic implementation of the foundations of upbringing for the education system [7]. The effectively organized extracurricular activities in these educational organizations can contribute to the achievement of the necessary positive upbringing results $[8,9]$. In this regard, the search for technologies for the correct and effective organizing the student teachers' upbringing is very important at the moment [3]. It became highly relevant especially during the period of lockdown and in connection with the gradual transition of the Russian higher school to a distance learning system.

\section{$2 \quad$ Literature Review}

\subsection{The main directions of the student teachers' upbringing}

The fundamental direction in the development of upbringing today is the revival of the traditions of the national upbringing system [4]. In particular, bridging the gap between generations within the family and establishing national values in the public consciousness and raising the social status of the family $[10,11]$. According to recent studies, the upbringing system modernization correlates with the teachers' social status level $[4,6]$. The idea of the teacher as a standard of social behavior, the bearer of unconditional moral and intellectual authority in the public consciousness is becoming very popular [1]. It is the level of development of the teachers' legal and political culture, their ability to correctly implement various decisions affecting the rights and interests of students that determine the further vector of the younger generation upbringing system $[3,12]$.

Experts define the upbringing of young people as an integral part of higher education, interconnected with learning, but also carried out as an independent activity [13]. It is aimed at personal development, creating conditions for self-determination and socialization of children based on socio-cultural, spiritual and moral values and rules and norms of behavior adopted in society in the interests of a person, family, society and state. There are some concepts focused on collective upbringing, based on the ideas of collective creative education and the design of upbringing systems [4, 14]. Upbringing in the youth environment is considered by these researchers as the creation of the educational organization upbringing system ensuring the unity of the students' socialization, upbringing and self-upbringing, development and self-development [5].

There are various basic guidelines in the areas of civic and patriotic upbringing as the foundations of youth upbringing $[3,11]$. On the other hand, experts identify the 
youth spiritual and moral development as a necessary component of a person's life by means of dignity, honor and honesty, conscientiousness, respect for the older generation formation [2, 4]. A special direction of researches is highlighted in terms of upbringing as the level of attitude towards people with disabilities and children with disabilities, tolerance in individual behavior [3, 14]. Physical activity and culture of physical health as an integral part of upbringing is determined by experts in the context of the internal motivation for a physical image and lifestyle level [8, 15]. Upbringing is inseparable from the culture of safe human life support, prevention of bad habits and the level of the healthy eating culture and sobriety improvement $[2,15]$. The professional component in the upbringing level is represented by the characteristics of labor education and professional self-determination demonstrating respect for work and labor achievements and deeds [4]. The level of upbringing is also interconnected with ecological culture and respect for nature and a sense of responsibility for the state of natural resources [1, 14]. Thus, based on various components of upbringing, the following structural model can be developed "See Fig. 1":

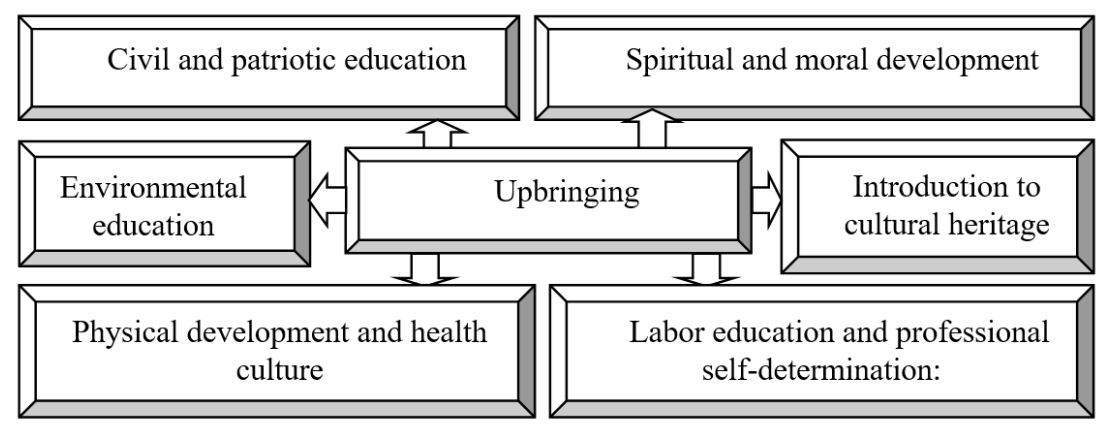

Fig. 1. Structural model of student teachers' upbringing

In the context of civilizational challenges, the upbringing system in Russia is aimed at strengthening the unity of the society, rethinking such values as civic identity, patriotism, and a responsible life position $[3,5]$. In this context, it is the professional training of a teacher in the university, institute or faculty educational space that strategically and technologically updates the upbringing [9]. This process is most effective in the context of an optimal combination of the Russian traditions, modern experience, achievements of scientific schools providing system-activity and cultural approaches to the personal potential of youth in higher education development $[2,16]$.

Thus, qualitative changes in the Russian system of upbringing can be achieved when student teachers' upbringing is implemented in the process of their training at the pedagogical university [6]. The synergistic interaction of the educational and extra-curricular environment of the higher pedagogical institution will increase the efficiency of ensuring the personal results of the student teachers' spiritual-moral and value-semantic orientations development [7, 17]. Formation of motivation for continuous personal growth, civic development of the personality, successful self-realization in life, society 
and profession, by means of extracurricular activities will achieve significant results in increasing the level of students' upbringing [3, 4].

\subsection{The main directions of extracurricular activities at the pedagogical institute}

The effectiveness of professional training and the educational and upbringing space of the institute in general is determined not only by professional knowledge and skills, but also by the implementation of these resources in their activities, including the extracurricular environment $[2,18]$. Comprehensively developed and formed abilities and value orientations in the pedagogical institute educational space determine higher productive level of personality development, and in the context of our research - the upbringing of a student teacher [5, 7].

The extracurricular component of the vocational institution space includes special educational, social and health-improving departments of the university [6]. Department for upbringing and social work, sports club, students and graduate students' trade union organization are in the center of this activity. There is a center for leisure and creativity and a center for student initiatives implementing leisure activities [5]. A student sports club, a service for students' socio-psychological support, a psychological club, a student nutrition complex, a sanatorium-preventorium, and a health center of the institute have been implemented in the field of physical activity and health saving [15]. Quality management, mentorship and support of this system are organized by the council for educational and social work including curators and tutors of academic groups, student self-government bodies [6]. This extracurricular activity can be represented in the form of a system model "See Fig. 2":

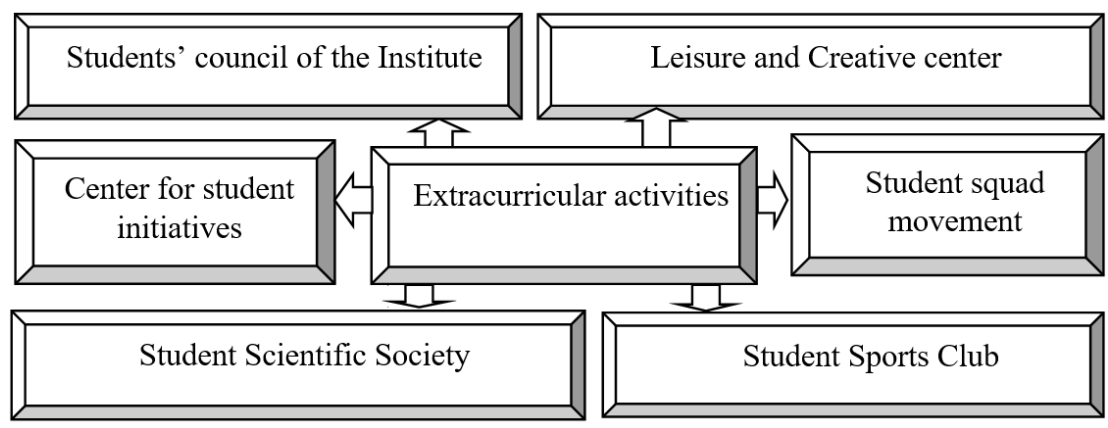

Fig. 2. System model of extracurricular activities of student teachers

The main mechanism of interaction between the elements of upbringing activity are subject-subject relations, focus on the content of future professional activity, actualization of positive emotional states, the presence of feedback based on interpersonal communication and pedagogical diagnostics, and problem-oriented presentation of information. 


\subsection{Extracurricular activities of the pedagogical institute based on the implementation of distance technologies}

The above-named directions of the extracurricular environment are engaged in improving the quality of vocational training, using modern information technologies, based on the personality-oriented and individually-differentiated paradigm of education, $[19,20]$. This, in turn, allows positive adaptation of students to the educational process and distance learning at the institute, as well as influence the effectiveness of the upbringing system as a whole [21,22].

In turn, each area of extracurricular activities presented in the model is divided into the following subdivisions. During the period of distance learning, the system of upbringing activities at the institute is implemented in the areas of full-time education, but with certain changes [23, 24]. Let's designate the main features of students' activity in each of the main directions of extracurricular activities [6,25]. Students 'council of the Institute: chatting to prepare and organizing a Self-Government Day at the Institute, organizing virtual extracurricular events throughout the year [26]. Center for student initiatives: preparation in groups and participation in competitions and Olympiads using digital technologies, participation in a project group for the creation of social grants, the creation of commercial projects online [16, 27]. Leisure and Creative center: online preparation for employment in children's camps, classes in creative circles using the Moodle system, online theater and participation in public speaking on stage [28]. Student squad movement: membership in the Sirius law enforcement detachment, participation in the construction squad, participation in the Phoenix patriotic search movement. This direction is implemented without the use of remote technologies, in the usual way. Student Sports Club: online training and participation in the "Ready for Labor and Defense" complex, implementation of wellness and fitness classes at home, individual classes in social networks and using other mobile content [15]. Student Scientific Society: participation in online scientific laboratories, design of scientific grants in specially created chats, group development of scientific articles.

\subsection{Hypothesis and purpose of the study}

The implementation of extracurricular activities of students in a non-standard mode, for example, in a distance format, requires a deep theoretical and practical analysis to create practical recommendations for further implementation experience [29, 30]. In this regard, the study formulated a hypothesis: If you develop and implement extracurricular activities of students in a distance format, then you can shape the upbringing of student teachers during the period of online professional training. Thus, the purpose of the study is to develop an upbringing system for students in a distance format and experimentally prove its impact on the main directions of upbringing of student teachers, in comparison with extracurricular activities in full-time mode. 


\section{Materials and Methods}

\subsection{Research design}

The study was carried out at the Faculty of Pedagogical and Art Education at the Glazov State Pedagogical Institute in two stages of 6 months. The first stage is from September 2019 to February 2020, the second stage is from February 2020 to July 2020.For the study, full-time students $(n=156)$ aged 19 to 24 were selected for the study, regardless of from the floor. All respondents study 3-4 courses for a bachelor's degree in pedagogical education in the profiles "Physical culture", "Biology", "Primary education", "Additional education" and "Life safety". Each participant in the study during the experimental work took an active part in extracurricular activities and gave written consent to participate in the study. During the first stage of the fall academic semester, the respondents actively implemented extracurricular activities in all areas in fulltime format. During the second phase of the spring semester, extracurricular activities were implemented based on distance technology during the period of self-isolation caused by the spread of COVID-2019. At the stage of self-isolation, students took an active online part in extracurricular activities in the same areas in which they carried out extracurricular activities earlier without a self-isolation regime until February 2020.

\subsection{Measurement instrument}

Diagnostic procedures for analyzing the level of formation of indicators of upbringing were carried out on the basis of analysis of data from respondents to Facebook and VKontakte social networks [26, 27]. Preliminary monitoring prior to the study was carried out in September 2019. Interim diagnosis was carried out between the first and second stages of the study in February 2020. The final monitoring was carried out after the experiment in July 2020. Monitoring was carried out based on the analysis of two diagnostic procedures. The first procedure included self-analysis by each study participant of their individual page to Facebook or VKontakte social networks [27, 29]. The second diagnostic procedure included an expert comparative analysis of the data obtained for the first diagnosis and the analysis of data from the social network of each respondent using a special monitoring sheet $[15,28]$. An example of a diagnostic selfexamination procedure to Facebook or VKontakte social networks "See Table 1": 
Table 1. Diagnostics of the self-analysis of an individual page to Facebook or VKontakte social networks in the patriotic direction

\begin{tabular}{|c|c|c|c|}
\hline $\begin{array}{l}\text { Self-analysis by individual page to Facebook or } \\
\text { VKontakte social networks }\end{array}$ & \begin{tabular}{|c|c|} 
Yes & $\begin{array}{c}\text { More Yes } \\
\text { than No }\end{array}$ \\
\end{tabular} & $\begin{array}{l}\text { More No } \\
\text { than Yes }\end{array}$ & No \\
\hline $\begin{array}{l}\text { 1. Is there (was) whether you have a patriotic theme in the "status" on your } \\
\text { page }\end{array}$ & & & \\
\hline 2. The presence of photos (your personal) on patriotic topics on your page & & & \\
\hline 3. The presence of videos (your personal) on patriotic topics on your page & & & \\
\hline 4. Is there (was) a patriotic theme in your "Personal" on your page & & & \\
\hline $\begin{array}{l}\text { 5. Is there (was) a patriotic theme "on the wall" and in the "news" on your } \\
\text { page }\end{array}$ & & & \\
\hline $\begin{array}{l}\text { 6. Do you leave patriotic information on other pages (bookmarks, meetings, } \\
\text { applications, subscriptions, etc.) }\end{array}$ & & & \\
\hline 7. Do you leave comments on patriotic topics on other pages & & & \\
\hline $\begin{array}{l}\text { 8. Do you use the content posted on the social network for patriotic educa- } \\
\text { tion }\end{array}$ & & & \\
\hline $\begin{array}{l}\text { 9. Patriotic information posted on the pages of people you don't know leaves } \\
\text { you indifferent }\end{array}$ & & & \\
\hline 10. Do you put "Likes" on patriotic information on other pages & & & \\
\hline 11. Do you participate in "groups" (discussions) on patriotic topics & & & \\
\hline $\begin{array}{l}\text { 12. Do you have a positive attitude to the dissemination of patriotic infor- } \\
\text { mation in social networks? }\end{array}$ & & & \\
\hline $\begin{array}{l}\text { 13. Have you disseminated patriotic information to other pages (video, } \\
\text { photo, etc.) }\end{array}$ & & & \\
\hline 14. Do you use a social network to search for patriotic information & & & \\
\hline
\end{tabular}

The data processing was carried out on the basis of summing up all the points scored by the respondents on the following scale: "Yes" - 3 points, "More Yes than No" - 2 points, "More No than Yes" - 1 point, "No" - 0 points -lov (except for question 9 - "Yes" - (- 2) points, "More Yes than No" - (- 1) point, "More No than Yes" - 0 points, "No" 3 points). The test results were ranked according to three levels: high level - over 20 points, average level - from 10 to 20 points, low level - less than 10 points.

\subsection{Analyzing data}

The mathematical and statistical reliability of the data obtained for each direction of the formation of upbringing in student teachers of the obtained values was carried out using the information method SPSS Statistics 20. To implement a comparative analysis of the experimental intervention of the difference in the amount in each subgroup by levels (high, average and low), the statistical method was used chi-square $\left(\mathrm{X}^{2}\right)$ at $\mathrm{p}<0.01$ and $p<0.05$. A statistical study on the reliability of the obtained focus group data was carried out in comparison separately for each direction of upbringing (civic and patriotic upbringing, spiritual and moral development, familiarization with cultural heritage, physical development and health culture, labor education and professional self-determination, environmental education) between three diagnostic slices: September 2019, February 2020 and July 2020. 


\section{$4 \quad$ Results}

\subsection{Levels of upbringing formation in directions}

On the basis of a preliminary theoretical analysis and the creation of a structural model of students' upbringing, the main directions for each structural component of the upbringing of a student teacher were identified according to the following level characteristics.

Civil and patriotic upbringing includes three main interdependent directions in terms of levels: the level of formation of students' holistic worldview, Russian identity, respect for their family, society, state, spiritual and moral socio-cultural values adopted in the family and society, for national cultural and historical heritage and aspirations to its preservation and development [4]; the level of development of the legal and political culture of students, the expansion of their constructive participation in decision-making affecting their rights and interests [3]; the level of development of motives, moral and semantic attitudes of the individual, allowing to resist extremism, xenophobia, discrimination on social, religious, racial, national grounds, interethnic and inter-confessional intolerance [1].

One of the key areas of upbringing of a student teachers is spiritual and moral development, which includes the improvement of four synergistically interrelated levels: the development of responsibility and choice in the system of collectivism and solidarity, the spirit of mercy and compassion, the habit of caring for children and adults experiencing difficulties in life [13]; the formation of an activity-based positive attitude towards people with disabilities and disabled children, through overcoming the psychological barriers that exist in society in relation to people with disabilities [15].

Introduction to the cultural heritage is the basis of the cultural upbringing of students at the university: the level of formation of a sense of dignity, honor and honesty, conscience, respect for the older generation, teacher, parents, peers, other people [6]; the level of familiarity with classical and contemporary domestic and world works of art and literature [9]; the level of support for ethnic cultural traditions and folk art [2].

In the field of health preservation, the main direction is physical development and health culture, ranked according to the following levels of education formation: the formation of students' responsible attitude to their health and motivation in a healthy lifestyle and lifestyle [15]; the formation of a culture of safe life through the prevention of bad habits and the development of a culture of healthy eating and sobriety [5]; development of internal positive motivation for an active physical culture lifestyle, sports [15].

In the field of professional development of a student teachers, the main type of upbringing is focused on the levels of labor education and professional self-determination: respect for work, people of labor, labor achievements and feats, the development of skills, skills and competencies of self-service, performance of labor social and domestic duties [2]; the need to work, a conscientious, responsible and creative attitude to various types of work and professional self-determination through involvement in socially significant activities for a meaningful choice of profession [7]; development of the ability to work together with others, to act independently, actively and responsibly, mobilizing 
the necessary resources, correctly assessing the meaning and consequences of their actions [18].

Environmental education is a necessary direction in the full-value level of upbringing of the future teacher, represented by the following levels: the formation of environmental culture and respect for the native land; the formation of the ecological picture of the world through the development of the desire to protect and preserve nature [14]; a sense of responsibility for the state of natural resources and their rational use in social interaction [6].

In turn, each level of the corresponding direction of the upbringing of the student teachers is ranked according to three levels of the formation of a student's upbringing in a pedagogical institute: high, average and low.

\subsection{Validation results}

To identify the comparative effectiveness of extracurricular activities in two different formats (full-time and distance) in different areas of upbringing of future teachers, all respondents of the experimental sample were tested based on the analysis of respondents' data to Facebook and VKontakte social networks. For a comparative analysis, formulating conclusions and practical recommendations, diagnostic monitoring of the first and second stages of the study was carried out. Summary results of the experiment in all areas of student upbringing "See Table 2".

Table 2. The results of the experiment for each direction of upbringing of student teachers

\begin{tabular}{|c|c|c|c|c|c|c|c|c|}
\hline \multirow{5}{*}{\begin{tabular}{|l|}
\multicolumn{1}{|c|}{$\begin{array}{c}\text { Directions of } \\
\text { upbringing }\end{array}$} \\
$\begin{array}{l}\text { Civil and patriotic } \\
\text { education }\end{array}$ \\
\end{tabular}} & \multirow{4}{*}{\begin{tabular}{|l|}
\multicolumn{1}{|c|}{ Stage } \\
September 2019 \\
February 2020 \\
\end{tabular}} & \multicolumn{3}{|c|}{ Number of respondents } & \multirow{2}{*}{\multicolumn{2}{|c|}{$\mathbf{X}^{2}$}} & \multirow{2}{*}{\multicolumn{2}{|c|}{$\mathbf{P} *$}} \\
\hline & & \multirow{2}{*}{\begin{tabular}{|c|} 
High \\
29 \\
\end{tabular}} & \multirow{2}{*}{$\frac{\text { Average }}{83}$} & \multirow{2}{*}{\begin{tabular}{|c|} 
Low \\
44 \\
\end{tabular}} & & & & \\
\hline & & & & & \multirow{3}{*}{12.83} & \multirow{3}{*}{8.43} & \multirow{3}{*}{$\begin{array}{c}<0.01 \\
\mathrm{p}=0.002\end{array}$} & \\
\hline & & 45 & 91 & 20 & & & & \multirow{2}{*}{$\begin{array}{c}<0.05, \\
\mathrm{p}=0.015\end{array}$} \\
\hline & July 2020 & 37 & 101 & 18 & & & & \\
\hline \multirow{3}{*}{$\begin{array}{l}\text { Spiritual and moral } \\
\text { development }\end{array}$} & September 2019 & 41 & 92 & 23 & \multirow{3}{*}{7.46} & & \multirow{3}{*}{$\begin{array}{c}<0.05 \\
\mathrm{p}=0.025\end{array}$} & \\
\hline & February 2020 & 39 & 108 & 9 & & \multirow[t]{2}{*}{1.63} & & $>0.05$ \\
\hline & July 2020 & 37 & 104 & 15 & & & & $\mathrm{p}=0.444$ \\
\hline \multirow{3}{*}{$\begin{array}{l}\text { Introduction to } \\
\text { cultural heritage }\end{array}$} & September 2019 & 51 & 58 & 47 & \multirow{3}{*}{2.24} & & \multirow{3}{*}{$\begin{array}{c}>0.05 \\
\mathrm{p}=0.328\end{array}$} & \\
\hline & February 2020 & 44 & 71 & 41 & & \multirow[t]{2}{*}{2.65} & & $>0.05$ \\
\hline & July 2020 & 37 & 65 & 54 & & & & $\mathrm{p}=0.266$ \\
\hline \multirow{3}{*}{$\begin{array}{l}\text { Labor education and } \\
\text { professional self-de- } \\
\text { termination }\end{array}$} & September 2019 & 61 & 73 & 22 & \multirow{3}{*}{13.29} & & \multirow{3}{*}{$\begin{array}{c}<0.01 \\
\mathrm{p}=0.002\end{array}$} & \\
\hline & February 2020 & 80 & 71 & 5 & & \multirow[t]{2}{*}{21.04} & & $<0.01$ \\
\hline & July 2020 & 45 & 100 & 11 & & & & $\mathrm{p}=0.001$ \\
\hline \multirow{3}{*}{$\begin{array}{l}\text { Physical } \\
\text { development and } \\
\text { health culture }\end{array}$} & September 2019 & 19 & 68 & 69 & \multirow{3}{*}{6.48} & & \multirow{2}{*}{$\begin{array}{l}<0.05 \\
\mathrm{p}=0.04\end{array}$} & \\
\hline & February 2020 & 36 & 62 & 58 & & \multirow[t]{2}{*}{7.87} & & $<0.05$ \\
\hline & July 2020 & 21 & 55 & 80 & & & & $\mathrm{p}=0.02$ \\
\hline \multirow{3}{*}{$\begin{array}{l}\text { Environmental } \\
\text { education }\end{array}$} & September 2019 & 40 & 99 & 17 & \multirow{3}{*}{5.46} & \multirow{3}{*}{0.23} & \multirow{3}{*}{$\begin{array}{c}<0.05 \\
\mathrm{p}=0.066\end{array}$} & \multirow{3}{*}{$\begin{array}{c}>0.05, \\
\mathrm{p}=0.893\end{array}$} \\
\hline & February 2020 & 54 & 94 & 8 & & & & \\
\hline & July 2020 & 57 & 90 & 9 & & & & \\
\hline
\end{tabular}

$\mathrm{P}^{*}: \mathrm{P}>0.05=\mathrm{X}^{2}<5.991 ; \mathrm{P}<0.05=9.21>\mathrm{X}^{2}>5.991 ; \mathrm{P}<0.01=9.21<\mathrm{X}^{2}$. 
As a result, during the implementation of experimental work at the first stage of the study (September 2019 - February 2020), a change in the number of respondents by level groups was revealed with statistical reliability in the following areas of upbringing of future teachers: civil and patriotic education $(<0.01, \mathrm{p}=0.002)$, spiritual and moral development $(<0.05, \mathrm{p}=0.025)$, labor education and professional self-determination $(<0.01, \mathrm{p}=0.002)$, physical development and health culture $(<0.05, \mathrm{p}=0.04)$, environmental education $(<0.05, \mathrm{p}=0.066)$. Only when educating young people in the direction of "introduction to cultural heritage" was there a statistical inaccuracy in comparing the data $(>0.05, p=0.328)$ after the first stage of the experiment. Hence, we can make a reliable conclusion that extracurricular activities in the traditional full-time format have a positive effect on the indicators of the upbringing of student teachers.

Analysis of the obtained statistical data after the second stage of the experimental work (February 2020 - July 2020) revealed a statistical change in the number of respondents by level groups in the negative direction in the following areas: civil and patriotic education $(<0.05, \mathrm{p}=0.015)$, labor education and professional self-determination $(<0.01, \mathrm{p}=0.001)$, physical development and health culture $(<0.05, \mathrm{p}=0.02)$. No statistically positive result has been obtained in any of the areas of student education. The insignificance of comparing the results at the second stage of the study was recorded in the following areas: spiritual and moral development $(>0.05, \mathrm{p}=0.444)$, introduction to cultural heritage $(>0.05, p=0.266)$, environmental education $(>0.05$, $\mathrm{p}=0.893$ ). Hence, it is possible to draw a statistically confirmed conclusion that extracurricular activities with the use of distance technologies in the self-isolation mode do not fulfill their target setting for the formation of the upbringing of future teachers. On the contrary, in some main areas it has a negative impact on civil and patriotic education, labor education and professional self-determination and physical development and health culture of students. According to these areas of upbringing, students showed a positive reliable shift at the first stage and a sharp directly proportional statistically substantiated decrease in the results in the opposite direction at the second stage when implementing distance technologies.

\subsection{Limitations}

The mathematical and statistical results of this scientific work obtained during the experiment are limited to a sample of one Glazov State Pedagogical Institute, which studied in bachelor's pedagogical areas. The sample of students of the Faculty of Pedagogical and Art Education declared in the experiment does not allow covering the entire target audience, since the research was conducted only in a limited space. In connection with this limited experimental intervention, the research conclusions can be recorded as experimental at the preliminary stage, and for the subsequent more individualized analysis, it is necessary to conduct an empirical experiment at all faculties of the pedagogical institute, as well as to study the experience of extracurricular activities in selfisolation in other pedagogical universities. A larger sample of respondents will provide statistically reliable information on the implementation of distance technologies in the process of upbringing future teachers in the educational and upbringing environment of a pedagogical organization. 


\section{Discussion}

The obtained results of the research work complement the data carried out earlier in the studies on certain aspects of the formation of youth upbringing on the basis of various non-traditional technologies [16, 19]. A number of authors place the main empirical emphasis on the development of family and collective upbringing as an additional factor in upbringing in an educational organization $[1,4]$. Experts experimentally popularize the best pedagogical experience of upbringing young people in educational groups in areas of professional training with the participation of family education [2]. Some researchers argue the need to improve the pedagogical culture of students on the basis of synergistic interaction between educational and public patriotic and spiritual organizations $[4,12]$. Through the system of support for student extracurricular clubs, clubs at the place of residence in dormitories, contributing to the preservation and revival of traditional moral values, other authors see a solution to the problem of upbringing the younger generation $[9,17]$. It is in this direction that the present research has been carried out, empirically proving the need for the implementation of extracurricular activities of students to improve the quality of professional training [6]. The statistical results of the study obtained in the course of the experimental intervention at the first stage substantiate the importance of the upbringing extracurricular system in the implementation of the upbringing component of the federal state educational standards. It is the full use of the upbringing potential of basic and additional educational programs in extracurricular time that increases the level of formation of students' holistic worldview and Russian identity, respect for society, for national cultural and historical heritage [3]. However, the study did not reveal a positive result in the level of formation and familiarity with classical and contemporary domestic and world cultural values and folk art. This result correlates with a number of empirical studies that correlate the formation of this characteristic of upbringing with a longer process, including continuous longterm education in the "school-institute" system $[5,16,18]$.

In the direction of the implementation of distance technologies, there is a significant amount of research on implementation in various areas of the educational process [17, 19]. To a lesser extent, a number of scientific works are focused on the study of online technologies in the implementation of the extracurricular upbringing process of professional training of students in the university space [11]. This direction is only gaining relevance and receives a scientific response in the research literature [7]. Research on the use of online technologies is focused on expanding the variability of upbringing systems aimed at shaping the individual trajectory of student personality development, taking into account his needs, interests and abilities [1, 4]. Improving conditions for identifying and supporting gifted students on the basis of distance forms of students' inclusion in intellectual-cognitive, labor, socially useful, artistic, physical-sports and game activities based on using the potential of the extracurricular education system [2, 12]. Part of the research empirically proves the system of psychological and pedagogical conditions to support the socialization and education of future teachers through the expansion of upbringing opportunities of information resources [14, 23]. Nevertheless, despite the great possibilities of distance, mobile and information technologies in teaching students, there is a negative effect in the upbringing system of a pedagogical 
institute [30]. As the results of the study showed, this was especially true in the field of labor education and professional self-determination. During the period of self-isolation and the implementation of distance professional training, students' respect for work, the development of skills, skills and competencies of self-service, and the fulfillment of labor social and domestic duties significantly decreased. During this period, the need to work, a conscientious, responsible and creative attitude towards various types of work and professional self-determination has decreased. The results of the study revealed negative shifts among students in the implementation of digital technologies in the development of the ability to work together with others, in the implementation of acting independently, actively and responsibly, mobilizing the necessary resources, correctly assessing the meaning and consequences of their actions.

The presented research is actively involved in a wide discussion of the use of social networks in the implementation of the educational process of a pedagogical university $[26,27]$. Experts empirically substantiate the need to use social networks in certain areas of educational and extracurricular activities [28, 30]. Many empirical studies of experts are devoted to the processing of training data and the analysis of information of educational and entertainment content for educational purposes [21, 25]. The necessity of using individual youth accounts for the purposes of public and environmental safety is empirically proved [19]. Diagnostics of individual pages of data users to Facebook and VKontakte social networks is most popular in economics and certain types of technical sociology [25, 24]. However, in this study, an attempt was made to apply data to Facebook and VKontakte social networks in educational science. Self-analysis and expert analysis, implemented in this study, made it possible to reveal the reliability of the innovations proposed in the study in the upbringing system for the implementation of distance technologies in the extracurricular activities of students - future teachers. The presented experience in the implementation of diagnostic procedures to Facebook and VKontakte social networks can be used to monitor the quality of education and socialization of students in other areas of undergraduate studies.

\section{Conclusion}

Thus, the experimental study is the author's paradigm for the formation of youth upbringing in extracurricular activities at a pedagogical institute based on the use of distance technologies. The structural content of upbringing presented in the model includes six synergistically interrelated areas: civil and patriotic education, spiritual and moral development, introduction to cultural heritage, labor education and professional self-determination, physical development and health culture, environmental education. In turn, the study developed a structural model of extracurricular activities, which, in the process of practical implementation, is empirically investigated for experimental intervention.

The upbringing student system developed in the research was tested in two formats of implementation: in full-time format at the first stage of the research and in a distance format in the second half of the research. The statistical data obtained during the study confirm the effectiveness of the implementation of extracurricular activities for the 
formation of the upbringing of future teachers only in full-time format. The introduction of distance technologies in the implementation of upbringing extracurricular activities does not have a positive effect on students, but in some areas it has an opposite negative effect.

For the pedagogical education system in the theoretical aspect, this study serves as a reliably confirmed scientific justification and methodological basis for improving the quality of professional training of future teachers in the field of upbringing. The theoretical value of the idea is based on the need to exclude the introduction of distance technologies in the process of upbringing students in the modern conditions of Russian higher education. Further empirical and research search for optimal and effective distance and digital technologies, adapted for the educational activities of students, to increase the effectiveness of the upbringing of future teachers is needed. The practical significance of the study is determined by the extensive use of the author's experience in introducing a self-analysis and monitoring system into the educational process through the use of Facebook and VKontakte social networks. The practical results of the study create the basis for the modernization of professional pedagogical education in the extra-curricular aspect, improving the content, structure and self-control, creating new psychological and pedagogical situations for the formation of an upbringing system.

\section{$7 \quad$ Acknowledgement}

The authors would like to sincerely thank the participants who took part in this study for their enthusiastic efforts.

\section{$8 \quad$ References}

[1] Muhammedovna, F. S. (2020). Components of interest and professional thinking in future teachers. International Journal of Psychosocial Rehabilitation, 24(5): 5962-5970. https://doi.org/10.37200/ijpr/v24i5/pr2020571

[2] Dulmukhametova, G. F., Sattarova, A., Fakhrutdinov, R. R., Khairutdinov, R. R. (2019). National self-consciousness of students in higher educational studies in the republic of tatarstan by means of humanitarian disciplines. Humanities and Social Sciences Reviews, 7(6): 1-5. https://doi.org/10.18510/hssr.2019.761

[3] Nagovitsyn, R. S., Bartosh, D. K., Ratsimor, A. Y., Maksimov, Y. G. (2018). Formation of Social Tolerance Among Future Teachers. European Journal of Contemporary Education, 7(4): 754-763. https://doi.org/10.13187/ejced.2018.4.754

[4] Belentsov, S. I., Gribanova, V. A., Tarasova, N. V., Kopylova, T. Y. (2019). Conditions and factors of the development of creative civic engagement of students. European Journal of Contemporary Education, 8 (2): 409-417. https://doi.org/10.13187/ejced.2019.2.409

[5] Galustyan, O. V., Kirik, V. A., Mazacova, N. (2019). Partnership of University and Schools Within the Preparation of Future Teachers. International Journal of Emerging Technologies in Learning, 14(17): 153-161. https://doi.org/10.3991/ijet.v14i17.10829

[6] Nagovitsyn, R. S., Ratsimor, A. Y., Bartosh, D. K., Neverova, N. V. (2019). Modernization of Regional Continuing Pedagogical Education in the «School-College-Institute». European 
Journal of Contemporary Education, 8(1): 144-156. https://doi.org/10.13187/ejced.2019. $\underline{1.144}$

[7] Sharzadin, A., Utebayev, I., Syzdykova, N., Shaushekova, B., Kossybayeva, U., Mukhatayev, A., Kurymbayev, S. (2019). Teaching Internship in Math Teacher Education. International Journal of Emerging Technologies in Learning, 14(12): 57-70. https://doi.org/ $\underline{10.3991 / i j e t . v 14 i 12.10449}$

[8] Gong, K. (2020). Extensible Strategies and Their Performance for Mental Health Education in Colleges. International Journal of Emerging Technologies in Learning, 15(9): 205-218. https://doi.org/10.3991/ijet.v15i09.14037

[9] Rybakova, L.A., Valeeva, R.A. (2014). The Role of Youth Organization in the Development of Higher Educational Institutions Students' Humanistic Value Orientations. Book Series: Procedia Social and Behavioral Sciences, 141, 817-821. https://doi.org/10.1016/j.sbspro. 2014.05.142

[10] Valeeva, R. A., Koroleva, N. E., Sakhapova F. K. (2016). Case-study of the High School Student's Family Values Formation. International Journal of Environmental and Science Education, 11(7), 1641-1649.

[11] Aznar-Díaz, I., Hinojo-Lucena, F. J., Cáceres-Reche, M. P., Romero-Rodríguez J. M. (2020). Pedagogical Approaches in the Knowledge Society: The Flipped Classroom Method for the Development of Creativity and Dialogical Learning. International Journal of Emerging Technologies in Learning, 15(3): 4-14. https://doi.org/10.3991/ijet.v15i03.11664

[12] Buddel, N. A. (2018). 'Teaching' the path towards university: understanding student access through storied-futures and meritocratic grand narratives. British Journal of Sociology of Education, 39(1): 16-31. https://doi.org/10.1080/01425692.2017.1302315

[13] Tagunova, I. A., Selivanova, N. L., Valeva, R. A. (2016). The Category of Upbringing in Russian and Western Studies. Mathematics Education, 11(1), 3-11.

[14] Prevot, A. C., Clayton, S., Mathevet, R. (2018). The relationship of childhood upbringing and university degree program to environmental identity: Experience in nature matters. Environmental Education Research, 24(2): 263-279. https://doi.org/10.1080/13504622. 2016.1249456

[15] Nagovitsyn, R. S., Tutolmin, A. V., Maksimov, Y. G., Dimova, I. A., Karoyan, A. A., Skryabina, D. Y., Volkov, S. A. (2019). Motivation for physical activity of people of different ages. Gazzetta Medica Italiana - Archivio per le Scienze Mediche, 178(10): 799-806. https://doi.org/10.23736/s0393-3660.18.03965-7

[16] Aikina, T. Y., Bolsunovskaya L. M. (2020). Moodle-Based Learning: Motivating and Demotivating Factors. International Journal of Emerging Technologies in Learning, 15(2): 239248. https://doi.org/10.3991/ijet.v15i02.11297

[17] Denizalp, H., Ozdamli F. (2019). Determination of Student Opinions on Usage of Social Media and Mobile Tools in Student-Teacher, Student-Student Communication.International Journal of Emerging Technologies in Learning, 14(22): 19-28. https://doi.org/10.3991/ ijet.v14i22.11745

[18] Nurkhin, A., Pramusinto, K. H. (2020). Applying Blended Problem-Based Learning to Accounting Studies in Higher Education; Optimizing the Utilization of Social Media for Learning. International Journal of Emerging Technologies in Learning, 15(8): 22-39. https://doi.org/10.3991/ijet.v15i08.12201

[19] Hodgson, N., Ramaekers S. (2020) Digitisation, securitisation, and upbringing: interrelations and emerging questions. Ethics and Education. https://doi.org/10.1080/17449642. $\underline{2020.1822630}$ 
[20] Matos, J., Pedro, A., Piedade, J. (2019). Integrating Digital Technology in the School Curriculum. International Journal of Emerging Technologies in Learning, 14(21): 4-15. https://doi.org/10.3991/ijet.v14i21.10863

[21] Bello-Orgaz, G., Jung, J. J., Camacho, D. (2016). Social big data: Recent achievements and new challenges. Information Fusion, 28, pp. 45-59. https://doi.org/10.1016/j.inffus. $\underline{2015.08 .005}$

[22] Camacho, D., Panizo-Ledot, Á., Bello-Orgaz, G., Gonzalez-Pardo, A., Cambria, E. (2020). The four dimensions of social network analysis: An overview of research methods, applications, and software tools. Information Fusion, 63: 88-120. https://doi.org/10.1016/j.inffus. 2020.05.009

[23] Brown, K., Shephard, K., Warren, D., Hesson, G., Fleming, J. (2016). Using phenomenography to build an understanding of how university people conceptualise their communityengaged activities. Higher Education Research and Development, 35(4): 643-657. https://doi.org/10.1080/07294360.2015.1137880

[24] Shen, R., Wohn, D.Y., Lee, M.J. (2020). Programming Learners' Perceptions of Interactive Computer Tutors and Human Teachers, 15(9): 123-142. https://doi.org/10.3991/ijet. v15i09.12445

[25] Aleksandrova, Y. G., Parusheva, S. S. (2019). Social Media Usage Patterns in Higher Education Institutions - An Empirical Study. International Journal of Emerging Technologies in Learning, 14(05): 108-121. https://doi.org/10.3991/ijet.v14i05.9720

[26] Christofides, E., Muise, A., Desmarais, S. (2009). Information disclosure and control on Facebook: are they two sides of the same coin or two different processes? Cyber psychology $\&$ behavior: the impact of the Internet, multimedia and virtual reality on behavior and society, 12(3): 341-345. https://doi.org/10.1089/cpb.2008.0226

[27] Camacho, D., Luzón, M.V., Cambria, E. (2021). New research methods \& algorithms in social network analysis. Future Generation Computer Systems, 114: 290-293. https://doi.org/10.1016/j.future.2020.08.006

[28] Khan, H. U., Nasir, S., Nasim, K., Shabbir, D., Mahmood, A. (2021). Twitter trends: A ranking algorithm analysis on real time data. Expert Systems with Applications, 164: 113990. https://doi.org/10.1016/j.eswa.2020.113990

[29] Kaiser, C., Ahuvia, A., Rauschnabel, P.A., Wimble, M. (2020). Social media monitoring: What can marketers learn from Facebook brand photos? Journal of Business Research, 117: 707-717. https://doi.org/10.1016/j.jbusres.2019.09.017

[30] Tartari, E., Tartari, A., Beshiri, D. (2019). The Involvement of Students in Social Network Sites Affects Their Learning. International Journal of Emerging Technologies in Learning, 14(13): 33-46. https://doi.org/10.3991/ijet.v14i13.10453

\section{Authors}

Roman S. Nagovitsyn is a Doctor of pedagogical Sciences, Professor of the Department of Physical Education, Methodology and Sports in Glazov State Pedagogical Institute, Glazov, Russia.

Roza A. Valeeva is a Doctor of pedagogical Sciences, Professor of the Department of Pedagogy in Kazan Federal University, Kazan, Russia.

Aleksander Y. Osipov is a candidate of pedagogical Sciences, Assistant professor of the Department of Physical Culture, Siberian Federal University, Krasnoyarsk State 
Medical University named after professor V.F. Voyno-Yasenetsky, Siberian Law Institute of the Ministry of Internal Affair of Russia, Krasnoyarsk, Russia.

Mikhail D. Kudryavtsev is a Doctor of pedagogical Sciences, Professor of the Department of Siberian Federal University, Siberian Law Institute of the Ministry of Internal Affair of Russia, Reshetnev Siberian State University Science and Technology, Krasnoyarsk, Russia.

Larisa V. Zakharova is a candidate of pedagogical Sciences, Assistant professor of the Department of Physical Culture, Siberian Federal University, Krasnoyarsk, Russia.

Article submitted 2020-10-08. Resubmitted 2020-11-25. Final acceptance 2020-11-26. Final version published as submitted by the authors. 